\title{
IMPLEMENTATION OF PRODUCTION SYSTEM DESIGN IN HOUSE BUILDING PROJECTS: A LEAN JOURNEY IN CHILE
}

\author{
Karina B. Barth ${ }^{1}$, Marcus P. Sterzi ${ }^{2}$, Carlos T. Formoso ${ }^{3}$, \\ Juan I. Alliende ${ }^{4}$, Daniela Bertín ${ }^{5}$ and Jorge Del Rio ${ }^{6}$
}

\begin{abstract}
Production system design (PSD) is a key process at the beginning of any manufacturing effort. It can be regarded as an initial planning task that involve a set of decisions that play an important role in the implementation of core Lean concepts, such as pull production, batch size, takt time. Despite its importance, very little attention is usually given to PSD in construction projects, and its relationship with the implementation of the Last Planner System (LPS). This article reports the experience of a construction company that has implemented PSD and the LPS, as part of the development of an improvement program in production management based on the Lean Philosophy. This company is based in Chile, and its core business is the development and construction of residential building projects. The implementation of PSD, and the LPS were the means for the adoption of a number of Lean principles and concepts, including pull production, takt time, work-in-progress control, reduction of batch size, and process transparency. Six main benefits of implementing PSD have been identified: (i) formalizing and making explicit planning decisions; (ii) reduction in uncertainty; (iii) improving planning accuracy; (iv) facilitating the adoption of cycle times and takt time control; (v) increasing the engagements of stakeholders; (vi) improving production stability. A set of practices were proposed for implementing PSD and these were classified according to decision categories.
\end{abstract}

\section{KEYWORDS}

Production System Design (PSD); Last Planner ${ }^{\circledR}$ System (LPS); Production Planning Control; Takt Time Planning; Location-based Planning and Control

1 PhD Candidate, NORIE, Federal University of Rio Grande do Sul, Brazil, Consultant and Managing Partner at LD Consulting, kbertotto@gmail.com, orcid.org/0000-0001-9612-6246

2 MSc, NORIE, Federal University of Rio Grande do Sul, Brazil, Consultant and Managing Partner at LD Consulting, marcus@1dconsulting.com.br, orcid.org/0000-0002-2235-944X

3 Professor, Building Innovation Research Unit - NORIE, Federal University of Rio Grande do Sul, Brazil, formoso@ufrgs.br, orcid.org/0000-0002-4772-3746

4 Engineer, Innovation Department, Socovesa Group, jialliende@socovesa.cl, orcid.org/0000-00029844-2143

5 Engineer, Management Control Department, Socovesa Group, dbertin@socovesa.cl, orcid.org/00000002-5994-7392

6 Engineer, General Construction Manager, Socovesa Group, jdelrio@socovesa.cl, orcid.org/0000-00023450-830X 
Implementation of Production System Design in House Building Projects:

a Lean Journey in Chile

\section{INTRODUCTION}

The development of a structured planning process before the start of the construction stage can potentially bring substantial benefits to production management and increases the possibility of reaching the established goals. Differently from the planning exercises that are made during construction, this initial planning effort should involve decisions concerned with the design of production systems, by considering some core Lean concepts, such as pull production, batch size, takt time.

According to Schramm et al. (2006) and Ballard et al. (2001a), Production System Design (PSD) translates the production strategy into a set of decisions, which establishes a structure to manage different activities, and creates conditions for control and improvement. Some of these decisions establish facilities and equipment, resource capacity, technologies, and the infrastructure that are necessary for carrying out the production stage (Alves et al. 2006; Schramm et al. 2006). Ballard et al. (2007) define PSD as "the development of operation and process design in alignment with product design, the structure of supply chains, the allocation of resources, and design-forassembly efforts" (Ballard et al. 2007). Therefore, PSD represents an important managerial stage that must be carried out in advance of production activities in order to achieve better results during construction stage. PSD should involve a set of interconnected decisions, rather than isolated decisions, considering the need to improve of the production system as a whole (Schramm et al. 2004). Depending on the degree of repetitiveness of construction projects, it may be carried out at the level of the company, for a family of projects, or for single projects (Schramm et al. 2004).

The main benefits of PSD, pointed out in the literature are: reduction of uncertainty through a systemic view of the production system; generating input information for the long-term plan, based on a flow view; and reflecting the way the project will be executed (strategy). When applied to support the adoption of customization of housing units, PSD can potentially reduce the negative impact of design changes in production efficiency and reliability (Schramm et al. 2009). Furthermore, the development of a PSD can potentialize the benefits of the Last Planner ${ }^{\circledR}$ System (LPS), providing a wider view of the production system and allowing the early identification of a larger range of problems (Frandson et al. 2015).

Despite its importance, most construction companies do not carry out a PSD in a broad and explicit way (Draper and Martinez 2002). Many key decisions related to PSD are made informally, too late or without considering interactions with other decisions (Schramm et al. 2004). Moreover, due to the lack of participation of different stakeholders, some decisions are not properly communicated to people in charge of planning, and commitments are not formalized. As a consequence, the definition of tasks to be carried out is based on the experience of construction managers (Ballard et al. 2007) or on longterm project plans that have been produced without considering some core production management principles (Frandson et al. 2013).

The literature on PSD is relatively scarce and fragmented. Several definitions exist for PSD and there are other terms, such as work structuring (Ballard et al. 2001b; Tsao et al. 2004), design for production (Maneschi and Melhado 2010), and construction operations design (Hartmann et al. 2008). Likewise, some PSD practices are often included as part of other managerial processes, such as construction stage preparation, site layout and logistics planning, and phase scheduling (Ballard et al. 2007).

This article reports the experience of a construction company that has implemented PSD and the LPS along a period of 3 years, as part of the development of an improvement 
program in Lean Construction. The implementation of PSD and LPS were strongly based on a set of production management core concepts and principles, such as pull production, takt time, work-in-progress control, reduction of batch size, and process transparency, which usually do not get much attention in construction planning. The main contributions of this article are (i) the definition of the scope and potential benefits of PSD, and (ii) the proposition of a set of practices that can be used along the PSD stages, with emphasis on location-based planning and control (Frandson et al. 2015).

\section{PRODUCTION SYSTEM DESIGN IN CONSTRUCTION}

PSD represents an important stage in the conception of production systems for any type of industry. In manufacturing, for example, PSD allows quick commissioning of systems, quick repayment of invested capital, and fast delivery of new products to the market (Bruch and Bellgran 2013). According to those authors, superior PSD capabilities are crucial for competitive success. Regarding the construction industry, PSD has a key importance on the project cost and time performance of such process (Schramm et al. 2006).

In the context of the construction industry, Ballard et al. (2001b) proposed the idea of Work Structuring, which has some similarities with PSD. Work Structuring is divided into sub-processes generally occurring in the following order: chunking (decomposition of wholes into parts), sequencing, releasing, decoupling, and scheduling (Lean Construction Institute 1999). According to Tsao et al. (2004, p781), Work Structuring "generically describe how work on a project will create a product that meets customer needs". The idea of work structuring was later extended by Ballard et al. (2007), becoming more similar to PSD, including operations development and process design. Those authors pointed out the difference between PSD and the traditional organizational structuring and creation of work breakdown structures, which divide the work to be done, by including decisions about the production system. The purpose of PSD should be to make work flow more reliable and quick while delivering value to the customer (Ballard et al. 2007).

According to Ballard et al. (2007), these are the main outcomes of PSD: project execution strategies including global sequencing (or work trajectory); project organizational and contractual structure; configuration of supply chains; rough-cut operations design; and detailed operations design. Schramm et al. (2004) proposed a framework which contains a sequence of PSD decision categories for low-income housing projects: (a) definition of the base-unit installation sequence and capacity preplanning; (b) study of base-unit workflows; (c) definition of the execution strategy; (d) study of project workflows; (e) definition of production resources capacity; and (f) identification and design of critical processes. In spite of the sequential representation of these steps, Schramm et al. (2004) stressed that those decisions are usually interdependent. This framework was later extended to be applicable to complex construction projects, such as hospitals, industrial and commercial buildings, by adding an additional decision category, named identification of client requirements (Schramm et al. 2006). Schramm et al. (2006) also suggested the use of discrete event simulation and virtual prototyping as of testing alternative PSD, and as a way of making some decisions more transparent. More recently BIM 4D has also been used to support PSD, especially in clash detection (Biotto et al. 2015) and in the management of logistics of prefabricated building systems (Bataglin et al. 2020). 
The results from the implementation of PSD models have been promising. Schramm et al. (2006) stated that PSD helped deal with complexity and uncertainty in production management, by promoting discussion among stakeholders and allowing the explicit consideration of customer requirements in the definition of production processes. Ballard et al. (2007) pointed out that the development of a PSD helps to increase the reliability of planning and control systems and thereby significantly to improve performance. The lack of reliability in work flows introduces more uncertainty and increases the difficulty of managing production resources (information, labor, materials and equipment), resulting in more work in progress (WIP), and construction delays (Ballard et al. 2007).

Regarding the implementation of PSD, there are some critical factors that must be considered (Schramm et al. 2004): production managers should have a more strategic view, instead of being simply concerned with operational decisions; the execution strategy must be clearly communicated to production management staff and crews; visual management must be used for communicating plans and goals; the most critical uncertainties must be identified and effectively managed; the purpose of the supporting tools must be clearly defined before being implemented; and production plans should be simplified in order to be understood by work teams. Furthermore, Alves et al. (2006) pointed out the importance of having reliable data when designing production systems, so that buffer allocations and batch sizes can be accurately defined; and of understanding the nature of the project supply chain.

It is also important to clearly understand the connection between PSD and Planning and Control Systems. PSD must be carried out before Master Scheduling (Ballard et al. 2007) and should be considered as an input for long term plans. Additionally, the PSD should be the moment when critical processes are analyzed and hand-offs are stablished. After the beginning of the construction stage, phase scheduling is undertaken in order to integrate and coordinate various specialists' operations (Ballard et al. 2007). That level of planning plays a key role in understanding the sequence of activities for each construction stage, and getting the commitment of different stakeholders in relation to long term-plans (Ballard 2000; Ballard and Howell 2003). However, some of these planning meetings might include some late tactical decisions about site installation, which should be moved to PSD.

\section{OVERVIEW OF THE IMPLEMENTATION PROCESS}

Founded in 1965, Socovesa is currently the largest real estate group in Chile and one of the largest in South America. It is a fully integrated company that buys land, designs and builds projects, and sells the end products. Most of the residential building projects delivered by Socovesa have a a high degree of repetitiveness, such as horizontal housing estates and vertical buildings. This company operates in 13 of the 15 regions of Chile, with more than a 100 projects in progress and sells more than 3,000 units per year. The company is promoting a major transformation process that will lead to a larger corporation with different brands that will focus on different customer segments.

A Lean Implementation Program has been carried out in the company with the support of a consultancy firm and a research institution, both from Brazil. This work is also part of a doctoral research on Performance Measurement Systems, that uses Design Science Research as the methodological approach. This paper reports the implementation process and presents a preliminary assessment of the impacts of this implementation program. Data have been collected by the research team and, in the near future, the main results achieved will systematically reported. 
The implementation program has been divided into three main phases: (i) assessment of existing situation; (ii) development and initial testing of the production management system in pilot studies; and (iii) implementation of PSD and LPS in several projects of the company and refinement of the production management system. Differently from other empirical studies on the implementation of PSD reported in the literature, this paper analyses an initiative of explicitly implementing PSD in several projects of the same organizations, representing a unique opportunity to make prescriptions on how to perform this process. Table 1 presents a brief description of the Implementation Program, including the descriptions of each phase, the projects involved, and evaluation mechanisms (which have been also used as sources of evidence in the research study).

Table 1: summary of implementation program

\begin{tabular}{|c|c|c|}
\hline Phase/Year & Projects Characterization & Evaluation mechanisms/ Sources of evidence \\
\hline $\begin{array}{c}1 \\
\text { Assessment of } \\
\text { existing } \\
\text { situation }\end{array}$ & $\begin{array}{l}\text { Number of Projects: } 2 \\
\text { A. Low Income Housing - } 160 \\
\text { dwellings } \\
\text { B. Median Income } \\
\text { Residential Building- } 216 \\
\text { dwellings }\end{array}$ & $\begin{array}{l}1 \text { day site visit per project: assessment of the current } \\
\text { planning and control systems through a an evaluation } \\
\text { protocol } \\
\text { Participant observation in } 1 \text { weekly planning session } \\
\text { per project } \\
4 \text { interviews per project: including top managers, } \\
\text { engineers and architects } \\
1 \text { interview with a board member } \\
1 \text { interview with the General Construction Manager } \\
\text { Analysis of the current company's system for planning } \\
\text { and control }\end{array}$ \\
\hline $\begin{array}{l}2 \\
\text { Development } \\
\text { and initial } \\
\text { testing of the } \\
\text { production } \\
\text { management } \\
\text { system }\end{array}$ & $\begin{array}{l}\text { Number of Projects: } 3 \\
\text { C. Low Income Housing - } 176 \\
\text { dwellings } \\
\text { D. Medium Income } \\
\text { Residential Building- } 110 \\
\text { dwellings } \\
\text { E. Medium Income } \\
\text { Residential Building- } 126 \\
\text { dwellings }\end{array}$ & $\begin{array}{l}\text { Participant observation in } 8 \text { PSD Meetings (4h each) } \\
\text { with project teams and/or stakeholders / project } \\
4 \text { PSD consultancy feedback meetings ( } 2 \mathrm{~h} \text { each) / } \\
\text { project } \\
\text { Participant observation in } 8 \text { lookahead meetings ( } 2 \mathrm{~h} \\
\text { each)/ project } \\
\text { Participant observation in } 12 \text { weekly planning session } \\
\text { (1.5h each)/ project } \\
12 \text { site visits / project } \\
8 \text { Lean workshops (5h each) with pilot project teams }\end{array}$ \\
\hline $\begin{array}{l}3 \\
\text { Implementation } \\
\text { of PSD and } \\
\text { Last Planner } \\
\text { and refinement } \\
\text { of the } \\
\text { production } \\
\text { management } \\
\text { system } \\
2018 / 19\end{array}$ & $\begin{array}{l}\text { Number of Projects: } 5 \\
\text { F. Low Income Housing }-224 \\
\text { dwellings } \\
\text { G. Low Income Housing - } 324 \\
\text { dwellings } \\
\text { H. Median Income Residential } \\
\text { Building - } 126 \text { dwellings } \\
\text { I. Median Income Residential } \\
\text { Building - } 129 \text { dwellings } \\
\text { J. Median Income Residential } \\
\text { Building - } 144 \text { dwellings }\end{array}$ & $\begin{array}{l}\text { Participant observation in } 12 \text { PSD meetings ( } 4 \mathrm{~h} \text { each), } \\
\text { with project teams and/or stakeholders per project } \\
6 \text { PSD consultancy feedback meetings ( } 2 \mathrm{~h} \text { each) / } \\
\text { project } \\
\text { Participant observation in } 10 \text { lookahead meetings ( } 2 \mathrm{~h} \\
\text { each) / project } \\
\text { Participant observation in } 10 \text { weekly planning session } \\
(1.5 \mathrm{~h} \text { each) / project } \\
10 \text { site visits / project } \\
10 \text { Lean workshops ( } 5 \mathrm{~h} \text { each) with program project } \\
\text { teams }\end{array}$ \\
\hline
\end{tabular}

\section{Phase 1 - Assessment OF EXISTing Situation}

The focus of Phase 1 was the analysis of the existing data from Production Planning and Control System, as the company did not have a systematic and explicit PSD. Several construction sites were visited. Interviews and meetings were carried out with top managers, architects/engineers, site supervisors and subcontractors. 
Data from two ongoing projects were also analyzed in detail. An overall assessment report was produced and presented to the company, concluding that the company had very limited success in the implementation of some elements of LPS in the previous two years. In fact, few LPS practices had been fully implemented and disseminated in the company, mainly due to the fact that they were misinterpreted from the lack of understanding of core concepts. For example, weekly planning meetings were held without the participation of subcontractors and weekly tasks planned did not have a specific start and end date. There was also confusion between some concepts of LPS, such as constraints and reasons for the non-completion of plans, and distortions on the way PPC was calculated.

\section{Phase 2 - DEVElopMent AND INITIAL TESTING OF THE PRODUCTION MANAGEMENT SYSTEM}

At the beginning of Phase 2, the company formed a group of representatives of different departments, named Lean Supporting Group (LSGroup), formed by two consultants, representatives from the Management Control Department and from the Innovation Department, and the General Construction Manager. The main activities developed in this Phase were: (i) selection of pilot projects; (ii) eight-week training course on Lean Construction for the pilot project teams; (iii) implementation of PSD in three pilot projects; (iv) implementation of LPS model in those three projects; and (vi) evaluation of the benefits of the implementation and proposition of PSD and LPS models for the whole company. As the consultants suggested the need for a more intensive Lean training program, the company decided to offer an in-company diploma course on Lean Construction for their employees, with emphasis on change management. Three editions of this course were offered by a Chilean university, one in Phase 2 and two in Phase 3.

\section{PhaSe 3 - IMPLEMENTATION OF PSD AND LPS}

The main activities carried out in Phase 3 were: (i) selection of projects for the second stage of implementation; (ii) definition of the sequence of implementation in projects in order to balance the capacity of the LSGroup; (iii) refinement of the PSD model; (iv) implementation of PSD in five new projects; (v) implementation of LPS model in those five projects; (vi) evaluation of results and standardization of PSD practices; and (vii) evaluation of the impact of the implementation by using a set of indicators, including LPS metrics.

Overall, the implementation process comprised several steps, including evaluation of existing practices in each project, development of improvements to existing practices, and testing of the proposed practices. Data collection included several sources of evidence to access the impact of implementation, according to Table 1 . Besides the pilot studies, other projects were encouraged to implement the proposed PSD model during this phase, with the support of the technical staff of the Management and Control Department, and without the participation of LSGroup.

\section{PSD MODEL}

The model proposed by Schramm et al. (2004) was used as the starting point for defining the PSD process at the company. In Phase 2, PSD was initially implemented in three pilot projects (projects C, D, and E), based on an adaptation of Schramm's PSD model to the demands of the production management teams of those projects. 
In fact, the decision was made to put more emphasis in the proposed model on location-based planning and control, when compared to previous models, such as Schramm et al. (2004). This need had been identified in Phase 1, due to the large amount of WIP that was detected in several projects, based on the application of WIP metrics, such as the Batch Completeness Index, and Heatmaps analysis. The proposed model also introduced some innovations in terms of standardized control tools for cycle time, takt time, WIP and synchronization. Moreover, a new decision category was included with the aim of enhancing layout and logistics planning. This category had minor emphasis on previous research on PSD.

As a result, the PSD company's model was divided into eight decision categories: (i) analysis and definition of construction sequence (base-unit); (ii) definition of resources and estimation of production capacity (base-unit); (iii) definition of workflows (base-unit); (iv) definition of the execution strategy; (v) layout and logistics planning; (vi) definition of workflows (whole project); (vii) identification and design of critical processes; and (viii) PSD review. After the implementation of PSD in those three projects, a Plan-DoCheck-Act (PDCA) cycle was carried out by involving a larger group of people in the discussion of its scope, concepts and tools, including managers of pilot projects and the LSGroup. A new version of the PSD process was defined and documented in a guidebook, to be followed in five other projects (projects F,G,H,I, and J). As suggested by Schramm et al. (2004), despite the fact that there is a sequence of steps, devising a PSD is an iterative process, being necessary to do some back-and-forth in order to review some initial decisions.

\section{PSD COMPANY MODEL}

The eight decision categories are described below by presenting the main tasks involved in each of them.

\section{Decision Category 1: Analysis and definition of construction sequence (base-unit).}

1.1. Define the base-unit (BU).

1.2. Define the construction sequence for BU: consider activities at the Master Schedule level of detail.

1.3. Define critical processes not included in BU (e.g.: facades, external works, urban development).

1.4. Collect data to establish the processes' duration considering information gathered from historical data and different stakeholders.

1.5. Define cycle time of the BU, based on sequence and estimates of activity duration.

Figure 1 presents the construction sequence for a BU in a Housing Project, using BIM for communicating clearly the steps defined in PSD.

\section{Decision Category 2: definition of resources and estimation of production capacity (base-unit).}

2.1. Define the necessary capacity of crews for each of the BU processes.

2.2. Define capacity and number of equipment for each of BU process: compare and select suppliers based on advantages and cost.

2.3. Establish production and transfer batch for each of BU process.

2.4. Identify limitations concerning critical processes. 


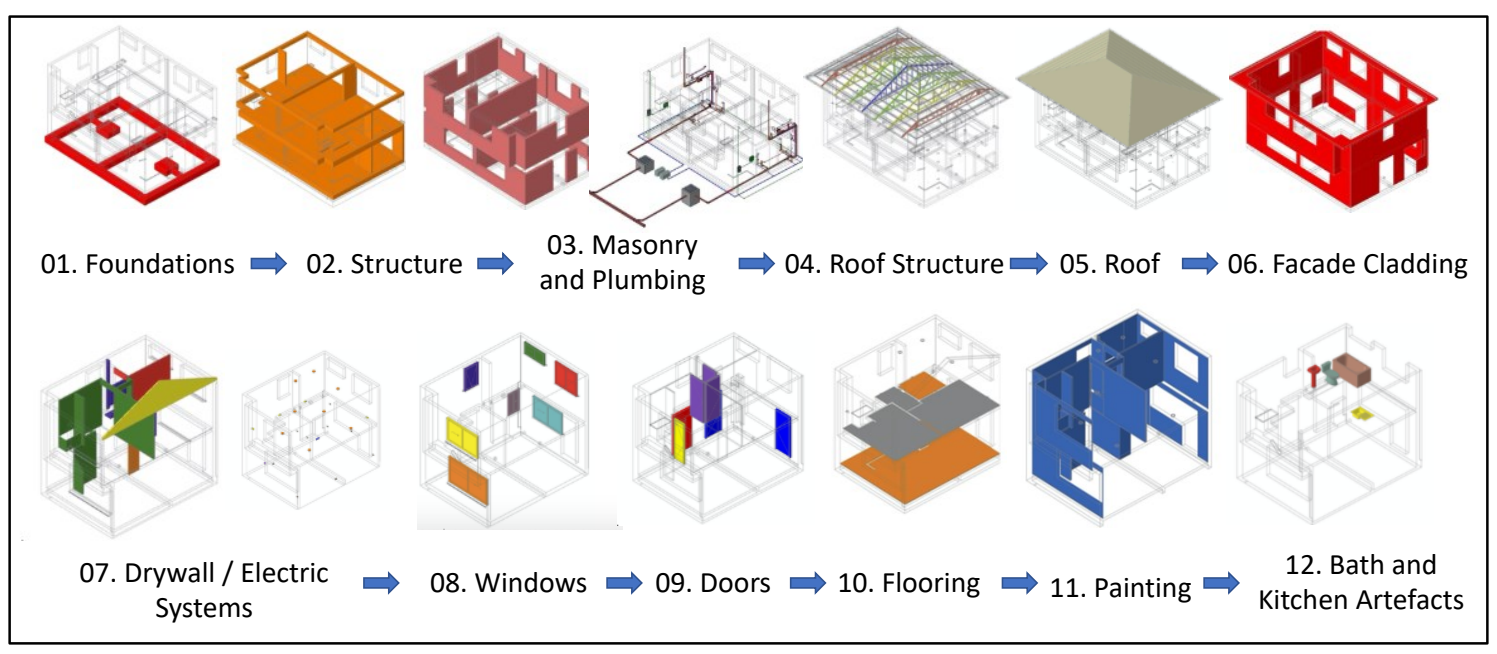

Figure 1: Construction sequence for BU presented in a BIM model

\section{Decision Category 3: definition of workflows (base-unit).}

3.1. Develop a precedence diagram for BU, based on previous steps: make a tradeoff analysis between product flow with (labor) workflow.

3.2. Analyze and reduce, if necessary, cycle time for BU.

\section{Decision Category 4: definition of the execution strategy.}

4.1. Divide the project into work areas, creating "small projects".

4.2. Define the execution path of BU processes.

4.3. Define the execution path of critical processes not included in BU.

4.4. Establish a location-based system for BU activities.

4.5. Define the number of workstations to be opened simultaneously or sequentially.

4.6. Devise execution strategy, including BU processes (e.g. superstructure, masonry, drywall elements, plumbing) and processes not included in BU (e.g. foundation, excavation, facades, external works).

\section{Decision Category 5: layout and logistics planning.}

5.1. Specify routes of movement for workers and equipment (horizontal and vertical).

5.2. Indicate off-loading facilities, temporary storage and storage areas.

5.3. Define construction site facilities (e.g. welcome facilities and entry control, site offices, meeting rooms, training facilities, wheel washing facilities, site canteen, sub-contractor facilities, waste management and recycling facilities).

5.4. Define pre-assembling/ pre-fabrication facilities, and facilities for the construction of mock-ups for testing.

5.5. Specify transport equipment logistics: assign movement, reach / radius, and load capacity of large equipment (e.g. cranes and bridge cranes, concrete placing booms, and elevators).

5.6. Specify logistics for accessing and off-loading: assign ramps, accesses, and turns for heavy transport equipment. 
The set of practices developed during this category may include a layout proposal for the main stages of the project, such as: (i) earthmoving and foundations, (ii) superstructure and facade, and (iii) interior construction and commissioning.

\section{Decision Category 6: definition of workflows (whole project).}

6.1. Develop a first version of the Line of Balance (LOB).

6.2. Analyze workflows and set the takt time based on the previously established execution strategy.

6.3. Balance the cycle time of the processes based on takt time.

6.4. Set buffers to decouple processes with high levels of uncertainty and variability.

6.5. Place project milestones in the Line of Balance.

\section{Decision Category 7: identification and design of critical processes.}

7.1. Identify critical processes that may limit the production capacity of the system or with limited individual capacity.

7.2. Design those processes including:

- Breaking down the BU in production batches.

- Virtual prototyping (using BIM) and/or Physical Prototyping.

- Assembling sequence.

- Detailing of operations indicating the number of workers.

- Preparing a workstation map.

7.3. Analyze production resource capacity: generate and analyze workforce and equipment histograms.

Figure 2 presents the workstation map for a critical process design.

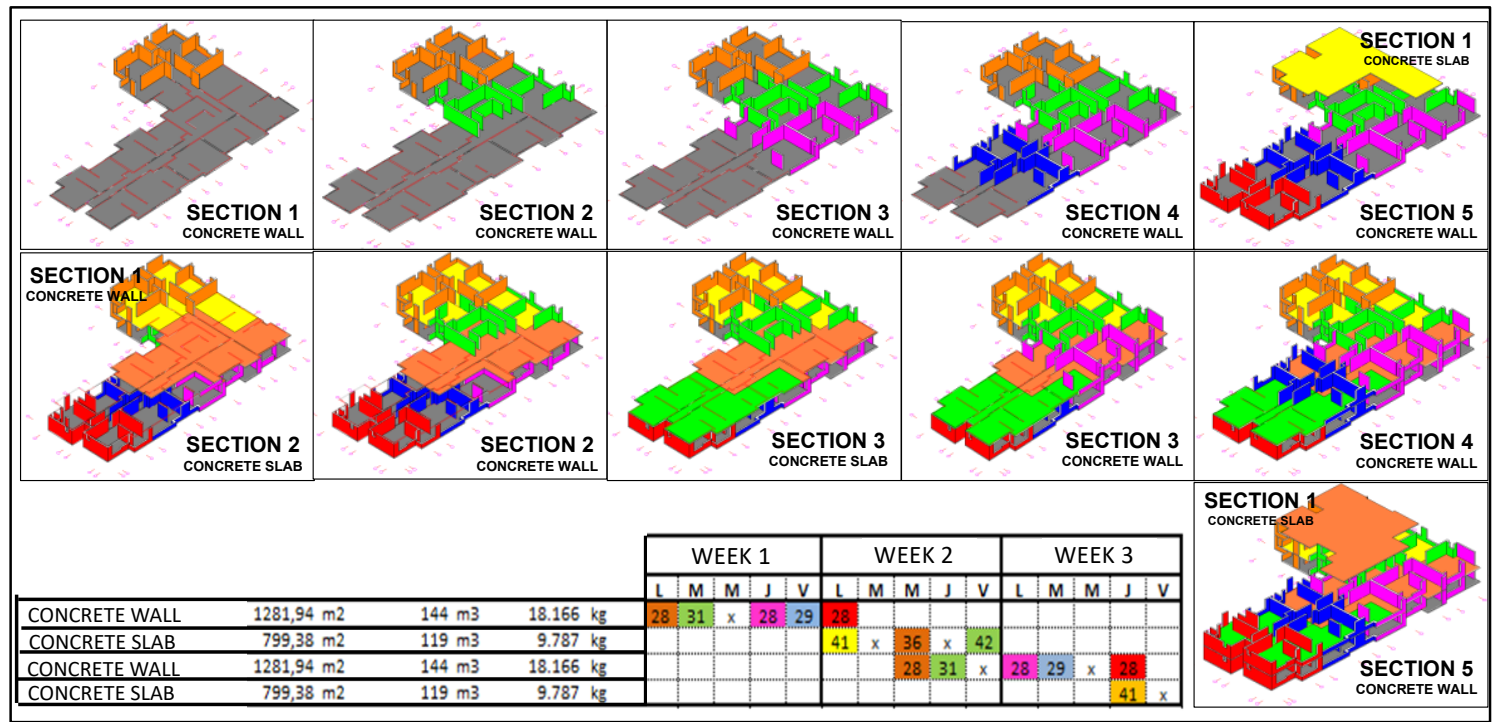

Figure 2: design of critical process for superstructure in a residential building

\section{Decision Category 8: PSD review.}

8.1. Review the outcomes of PSD, considering that all decision categories need to be balanced. 


\section{DISCUSSION ON THE BENEFITS OF IMPLEMENTING PSD}

At the end of Phase 3, a workshop was organized by the LSGroup, in order to identify and disseminate the benefits of implementing PSD. This was important to justify the efforts and resources invested in the Lean Implementation Program, and encourage production management staff to be engaged. Six main benefits of implementing PSD have been identified:

- Formalizing and making explicit planning decisions: key decisions on the design of the production system were made with the participation of or, at least, made explicit to the main stakeholders, making construction team aligned with the project's execution strategy. These decisions are based on the experience of several stakeholders and are used as a reference for other production planning decisions made during the execution stage.

- Reduction in uncertainty: PSD helps identifying production system limitations and critical processes. In fact, it adds a planning level higher that the master scheduling, rather than lower, as in phase scheduling. By doing that, several benefits can be achieved, such as proper management of uncertainties, integration of critical stakeholders in early planning decisions, and continuous generation of knowledge on the production system during the pre-construction stages.

- Improving planning accuracy: PSD has improved planning accuracy by exploring multiple alternatives of construction systems and subsystems, facilitating information flow through interactions among teams. One execution strategy must be selected, however, the others remain as alternatives in case the original one cannot be implemented due to unexpected changes in the project. In the proposed model planning accuracy can be monitored during the construction stage by batch adherence control metrics.

- Facilitating the adoption of cycle time and takt time control: PSD practices provide information that make it possible to implement takt time and cycle time control in a systematic way. Both may be extracted from the design of critical processes and controlled throughout rhythm deviation and cycle time variance indicators.

- Increasing the engagements of stakeholders: PSD should encourage the participation of managers, subcontractors, suppliers and other stakeholders during the pre-construction stage. As a result, the participants become more involved with PSD decisions, engaging them with Planning and Production Control. The impact of stakeholders engagement may be evaluated during the construction stage through WIP indicators, Batch Completeness Index and Last Planner metrics.

- Improving production stability: lack of stability is highly related to uncertainty and variability. Some PSD practices, such as buffer allocation and sizing, slack and WIP control, help mitigating some negative effects of random conditions on the progress and efficiency of project activities. For instance, the design of critical processes is a form of standardization, allowing the elimination of some variability and uncertainty (especially if associated with prototyping). 


\section{CONCLUSIONS}

In this article a practical approach for the implementation of the PSD adopted by a Chilean construction company was described, based on some core Lean concepts and planning and control best practices. Some ideas from the PSD model proposed by Schramm et al. (2004) and from Work Structuring, as defined by Tsao et al. (2004), were adapted to the specific context of the company.

Differently from other studies, the proposed model: (i) was tested and implemented on several residential projects in a systematic way; (ii) provides more emphasis on location-based planning and control, layout and logistics studies during pre-construction stages; (iii) advances in terms of cycle time, takt time, WIP and synchronization analysis before construction; (iv) generates information concerning the production system as a whole; (v) and produces a set of standardized tools to be used to monitor the implementation of PSD.

It is important to highlight that, although PSD requires a collaborative effort in the pre-construction stages, the proposed model do not seek to increase the level of detail of decisions in those stages. In other words, it does not conflicts with the adoption of different hierarchical planning levels, proposed by LPS.

\section{ACKNOWLEDGMENTS}

We would like to thank the Socovesa Group project teams for their commitment in the implementation process, and in special to engineer Javier Sanchez for his support and contribution to the Lean Implementation Program.

\section{REFERENCES}

Alves, T. da C. L., Tommelein, I. D., and Ballard, G. (2006). "Simulation as a tool for production system design in construction." Proc. of the 14th Ann. Conf. of Int'l Group for Lean Construction, Santiago, Chile, 341-353.

Ballard, G. (2000). "Phase Scheduling [White paper]." Lean Construction Institute White Paper 7, 7-9.

Ballard, G., Hamzeh, F. R., and Tommelein, I. D. (2007). The Last Planner Production Workbook-Improving Reliability in Planning and Workflow. Project Production Systems Laboratory, UC Berkeley, Berkeley, California, USA, 81.

Ballard, G., and Howell, G. (2003). "An update on last planner." Proc. of the 11th Ann. Conf. of Int'l Group for Lean Construction, Virginia, USA, 1-10.

Ballard, G., Koskela, L., Howell, G., and Zabelle, T. (2001a). "Production System Design in Construction." Proc. of the 9th Ann. Conf. of Int'l Group for Lean Construction, Singapore, Singapore, 1-15.

Ballard, G., Koskela, L., Howell, G., and Zabelle, T. (2001b). "Production System Design in Construction: work structuring revised." Lean Construction Institite White Paper 11, (2000), 1-15.

Bataglin, F. S., Viana, D. D., Formoso, C. T., and Bulhões, I. R. (2020). "Model for planning and controlling the delivery and assembly of engineer-to-order prefabricated building systems: Exploring synergies between lean and BIM." Canadian Journal of Civil Engineering, 47(2), 165-177.

Biotto, C. N., Formoso, C. T., and Isatto, E. L. (2015). "Uso de modelagem 4D e Building Information Modeling na gestão de sistemas de produção em empreendimentos de construção." Ambiente Construído, 15(2), 79-96. 
Bruch, J., and Bellgran, M. (2013). "Characteristics affecting management of design information in the production system design process." International Journal of Production Research, 51(11), 3241-3251.

Draper, J. D., and Martinez, J. (2002). "The Evaluation of Alternative Production System Designs with Discrete Event Simulation." Proc. of the 10th Ann. Conf. of Int'l Group for Lean Construction, Gramado, Brazil, 1-11.

Frandson, A., Berghede, K., and Tommelein, I. D. (2013). "Takt time planning for construction of exterior cladding." Proc. of the 21 th Ann. Conf. of Int'l Group for Lean Construction, Fortaleza, Brazil, 527-536.

Frandson, A. G., Seppänen, O., and Tommelein, I. D. (2015). "Comparison Between Location Based Management and Takt Time Planning." Proc. of the 23th Ann. Conf. of Int'l Group for Lean Construction, Perth, Australia, 3-12.

Hartmann, T., Gao, J., and Fischer, M. (2008). "Areas of application for 3D and 4D models on construction projects." ASCE, JCEM, 134(10), 776-785.

Lean Construction Institute. (1999). "Work Structuring." Lean Construction Institite White Paper 5, 1-15.

Maneschi, K., and Melhado, S. (2010). "Scope of design for production of partition walls and facade coverings." Architectural Engineering and Design Management, 6(1), 3-17.

Schramm, F. K., Costa, D. B., and Formoso, C. T. (2004). "The Design of Production Systems for Low-Income Housing Projects." Proc. of the 12th Ann. Conf. of Int'l Group for Lean Construction, Helsingør, Denmark.

Schramm, F. K., Rodrigues, A. A., and Formoso, C. T. (2006). "The role of production system design in the management of complex projects." Proc. of the 4th Ann. Conf. of Int'l Group for Lean Construction, Santiago, Chile, 227-239.

Schramm, F. K., Tillmann, P. A., Berr, L. R., and Formoso, C. T. (2009). "Redesigning the production system to increase flexibility in house building projects." Proc. of the 17th Ann. Conf. of Int'l Group for Lean Construction, Taipei, Taiwan, 347-358.

Tsao, C. C. Y., Tommelein, I. D., Swanlund, E. S., and Howell, G. A. (2004). "Work Structuring to Achieve Integrated Product-Process Design.” ASCE, JCEM, 130(6), 780789. 